\title{
Need for open access non-screening mammography in a hospital with a specialist breast clinic service
}

\author{
J J Curtin, M A Sampson
}

\begin{abstract}
Objective-Assessment of open access nonscreening mammography in a hospital with a breast clinic.
\end{abstract}

Design-Retrospective analysis of patients sent for first mammogram to our open access service by general practitioners and breast clinic in the year April 1989 to March 1990.

Setting-District general hospital serving 200000 people before the introduction of breast screening.

Subjects-361 symptomatic women referred directly by general practitioners and 226 women referred by the breast clinic for first, non-screening mammograms.

Main outcome measures-Radiographic reports on all patients. Final diagnosis in patients reported as having possible or probable neoplasm.

Results-Of the women referred directly by general practitioners one $(0 \cdot 2 \%)$ was reported as showing probable malignancy (later histologically confirmed) and $15(4 \%)$ as showing possible malignancy (on follow up none had proved malignancy). Of the women referred by the breast clinic $38(17 \%)$ were reported as showing probable malignancy (all had confirmed carcinomas) and $35(15 \%)$ as showing possible malignancy $(19(54 \%)$ had proved malignancy). 18 of the proved malignancies were in women under 50 years old, 26 were in women over 64 years, and 14 were in women of screening age. 54 $(93 \%)$ of the 58 patients with proved breast cancer and an abnormal mammogram had a discrete breast lump.

Conclusions-General practitioners accurately divided women into low and high risk groups, resulting in few abnormalities being detected in patients referred directly for mammography. This suggests that an open access non-screening mammography service for general practitioners is unnecessary in an area with a specialist breast clinic. The large proportion of cancers in women outside of screening age emphasises the need for such clinics.

Department of Radiology, Northwick Park Hospital, Middlesex HA1 3UJ

J J Curtin, MRCPI, registrar M A Sampson, FRCR, senior registrar

Correspondence to: Dr Curtin.

BMF 1992;304:549-51

\section{Introduction}

No data are available on the use of an open access mammography service for symptomatic women in a hospital that also provides a specialist breast clinic service. The paucity of data on this subject is a peculiar anomaly given the volume of data on screening mammography. We therefore studied the results of our open access service over one year. The breast screening programme did not start in our catchment area until shortly after the end of the study year.

\section{PATIENTS AND METHODS}

During 1 April 1989 to 31 March 1990, 587 symptomatic women were referred for their first mammogram: $361(61 \%)$ directly from general practitioners and 226
(39\%) from the breast clinic. Patients who had had previous mammograms were excluded from the study. Two views of each breast were obtained for all patients. Patients were not physically examined in the radiology department. We retrospectively analysed the age, reason for request, and radiographic report on al patients. Ten months after the end of the study period we obtained follow up data on all patients in whom the mammogram was reported as showing a possible or probable malignancy.

\section{Results}

The age distribution was similar in the two groups (table I). The mean age was 50 (SD 10.9) years for patients referred by general practitioners and 53.9 (13) years for patients from the breast clinic.

TABLE I-Age distribution of patients referred for mammography by general practitioners and breast clinic

\begin{tabular}{lcc}
\hline & \multicolumn{2}{c}{ No (\%) of patients referred by: } \\
\cline { 2 - 3 } Age (years) & General practitioner & Breast clinic \\
\hline$<40$ & $52(14)$ & $17(8)$ \\
$40-49$ & $134(37)$ & $87(38)$ \\
$50-64$ & $143(40)$ & $69(31)$ \\
$>64$ & $32(9)$ & $53(23)$ \\
\hline Total & 361 & 226 \\
\hline
\end{tabular}

Table II shows the number of abnormalities found according to age in the two groups. It also shows the results of biopsy or follow up in patients with probable malignancy (patients whose mammograms were essentially diagnostic of malignancy) and in patients with possible malignancy (those with suspicious features on the mammogram sufficient to warrant further assessment). Abnormalities were found in 73 of 226 patients referred from the breast clinic, of whom $57(78 \%)$ later proved to have carcinoma. In contrast, only 16 of 361 women referred by their general practitioners had an abnormality. The single proved malignancy was in the woman with the mammographically probable carcinoma.

Seventeen of the carcinomas in the breast clinic group and the one carcinoma in the general practitioner group were in women aged less than 50 years. This accounts for $31 \%$ of all the detected carcinomas. A further $26(45 \%)$ cancers were in women older than 64 , only $14(24 \%)$ being in women of screening age.

Table III gives the reasons for referral and relates these to mammographic findings. Of the 58 patients reported as having possible or probable malignancy who subsequently had carcinoma proved, 54 had a discrete mass, and in 42 of these women the clinical diagnosis was carcinoma before mammography. Of the remaining four, two had recent indrawing of the nipple, one had breast pain, and one had an area of localised nodularity. 
TABLE II-Mammographic findings and results of follow up in patients referred for non-screening mammography by general practitioners and breast clinic

\begin{tabular}{|c|c|c|c|c|c|c|}
\hline & \multicolumn{3}{|c|}{ No of patients referred by general practitioner } & \multicolumn{3}{|c|}{ No of patients from breast clinic } \\
\hline & Benign & Possibly malignant & Probably malignant & Benign & Possibly malignant & Probably malignant \\
\hline $\begin{array}{l}\text { Age group (years): } \\
<40 \\
40-49 \\
50-64 \\
>64 \\
\end{array}$ & $\begin{array}{r}51 \\
128 \\
135 \\
31 \\
\end{array}$ & $\begin{array}{l}1 \\
5 \\
8 \\
1 \\
\end{array}$ & 1 & $\begin{array}{l}13 \\
69 \\
49 \\
22\end{array}$ & $\begin{array}{r}6 \\
11 \\
8 \\
10\end{array}$ & $\begin{array}{r}5 \\
12 \\
21\end{array}$ \\
\hline All ages (\%) & $345(96)$ & $15(4)$ & $1(0 \cdot 2)$ & $153(68)$ & $35(15)$ & $38(17)$ \\
\hline $\begin{array}{l}\text { Results of follow up: } \\
\text { Benign } \\
\text { Malignant }\end{array}$ & $\overline{-}$ & 15 & 1 & $\overline{-}$ & $\begin{array}{l}16 \\
19\end{array}$ & 38 \\
\hline
\end{tabular}

TABLE III-Indications for mammography related to mammographic findings

\begin{tabular}{|c|c|c|c|c|c|c|c|c|}
\hline \multirow[b]{2}{*}{ Indications } & \multicolumn{4}{|c|}{ No of general practitioner referrals } & \multicolumn{4}{|c|}{ No of breast clinic referrals } \\
\hline & Benign & $\begin{array}{l}\text { Possibly } \\
\text { malignant }\end{array}$ & $\begin{array}{l}\text { Probably } \\
\text { malignant }\end{array}$ & Total & Benign & $\begin{array}{c}\text { Possibly } \\
\text { malignant }\end{array}$ & $\begin{array}{l}\text { Probably } \\
\text { malignant }\end{array}$ & Total \\
\hline Breast pain & 107 & 4 & & 111 & 25 & 4 & 1 & 30 \\
\hline Nodularity-usually localised & 76 & 2 & & 78 & 44 & 3 & & 47 \\
\hline Discrete breast mass & 51 & 6 & & 57 & 47 & 15 & 5 & 67 \\
\hline Mass clinically carcinoma & & & & & 2 & 10 & 32 & 44 \\
\hline Family history of breast cancer & 40 & & & 40 & 6 & & & 6 \\
\hline Hormone replacement therapy & 33 & & & 33 & 3 & 1 & & 4 \\
\hline Recent nipple indrawing & 8 & 1 & 1 & 10 & 7 & 1 & & 8 \\
\hline Clear nipple discharge & 7 & & & 7 & 6 & 1 & & 7 \\
\hline Bloody nipple discharge & 3 & 1 & & 4 & 7 & & & 7 \\
\hline Anxiety about breast cancer & 3 & 1 & & 4 & & & & \\
\hline Miscellaneous & 17 & & & 17 & 6 & & & 6 \\
\hline
\end{tabular}

None of the 52 patients aged less than 40 referred directly by their general practitioners had a malignancy shown by mammography. Five of the 17 women in this age group referred from the breast clinic did. Four of these had a discrete mass and one had recent nipple indrawing. In two women referred for mammography with "clinical carcinoma" the mammograms appeared normal. One of these women did have a carcinoma.

We estimate the cost of two view mammography at $£ 24$. At this price the NHS spent $£ 8664$ on 361 patients directly referred by their general practitioner over one year to detect one cancer.

\section{Discussion}

The belief that breast screening might make the question of open access mammography for women obsolete is clearly wrong given that most $(76 \%)$ of the cancers detected in this study, which was undertaken before screening was introduced, were in women outside of screening age. Significantly, $31 \%$ of the malignancies were in women aged less than 50 years - a finding similar to that quoted in a previous study of symptomatic women. ${ }^{1}$ This underlines the need for good diagnostic services for women outside the screening age who have symptoms. In addition there will be the problem of women in the screened population who develop symptoms in the interval between screens.

The number of abnormalities found in patients referred by general practitioners was no higher than would be expected from a first screen in the screening programme, where rates of $5 / 1000$ to $7 / 1000$ are reported. ${ }^{2-4}$ The general practitioners had therefore already selected out the patients with strongly suspicious features and referred them to the breast clinic for assessment. The 361 women referred directly for mammography thus represented those whom general practitioners thought were less likely or unlikely to have carcinoma. If none of these 361 women had been referred for mammography only one radiologically detectable carcinoma would have been missed. This one woman presented to her general practitioner with recent indrawing of the nipple and in the absence of open access mammography would probably have been referred to the breast clinic.

We used the term symptomatic loosely to include not only a genuine symptom such as pain but signs such as breast mass and known or putative risk factors such as hormone replacement therapy (table III). Almost all of the cancers detected by mammography were in women with physical signs. Previous reports have stressed that breast pain and nipple discharge, in the absence of physical signs, are poor predictors of mammographic abnormality or carcinoma and suggest that ignorance of these facts causes large numbers of unnecessary referrals for mammography and surgical assessment. ${ }^{56}$

It is well known that mammography will miss cancers, even in the presence of a palpable lump, ${ }^{7-10}$ and cases of delayed diagnosis of cancer due to undue trust being placed in mammography have been reported. ${ }^{112}$ One of the reports is from our breast clinic and details three cases in which mammography performed for general practitioners under the open access service missed cancers, falsely reassured the general practitioners, and caused significant delay in diagnosis. ${ }^{12}$ All three were in women in their 40 s who had palpable masses. Several studies have shown that "triple assessment" in the form of clinical examination, mammography, and fine needle aspiration provides the best approach for detecting breast cancer. ${ }^{13-17}$ In women aged less than 35 the role of fine needle aspiration is particularly important as it has been shown to be much more sensitive than mammography in this group. ${ }^{1617}$ The yield from fine needle aspiration, however, is operator dependent ${ }^{18}$ and must be done in a specialist breast clinic.

If the open access non-screening mammography service was closed we believe that general practitioners would safely manage most of the patients they now refer for mammography without the need for a further investigation or opinion. All patients with a discrete mass or recent nipple indrawing would need to be referred to the breast clinic, but this is unlikely to substantially increase the clinic's workload as we routinely recommend on our reports that all women with a discrete mass should be referred to the clinic, even if a mammogram is reported as normal. We think 
that mammography requested for women aged less than 50 because of risk factors such as a family history of breast cancer or hormone replacement therapy is screening mammography and could properly be included in the screening programme.

General practitioners have shown themselves to be very able in distinguishing high risk from low risk groups and referring the former to the breast clinic and the latter for mammography. This has rendered our open access mammography service virtually useless. We therefore believe that women in an area with a specialist breast clinic, which has experienced staff with access to good cytology and mammography services, are well served and do not need direct open access non-screening mammography.

1 Egeli RA, Urban JA. Mammography in symptomatic women 50 years of age and under, and those over 50. Cancer 1979;43:878-82.

2 United Kingdom Trial of Early Detection of Breast Cancer Group. First results on mortality reduction in the UK trial of early detection of breast cancer. Lancet 1988;ii:411-6.

3 Tabar L, Gad A. Screening for breast cancer: the Swedish trial. Radiology 1981;138:219-22.

4 Baines CJ, Miller AB, Wall C, McFarlane DV, Simor IS, Jong R, et al. Sensitivity and specificity of first screen mammography in the Canadian breast screening study: a preliminary report from five centres. Radiology 1986;160:295-8.
5 Devitt JE. False alarms of breast cancer. Lancet 1989;ii:1257-8.

6 Garstin WIH, Kaufman Z, Baum M. False alarms of breast cancer. Lance $1990 ; i: 299$

7 Martin JE, Moskowitz M, Milbrath JR. Breast cancer missed by mammography. Am f Radiol 1979;132:737-9.

8 Edeiken S. Mammography and palpable cancer of the breast. Cancer 1988;61:263-5.

9 Cahill CJ, Boulter PS, Gibbs NM, Price JL. Features of mammographically negative breast tumours. Br $\mathcal{F}$ Surg $1981 ; 68: 882-4$.

10 Wallis MG, Walsh MT, Lee JR. A review of false negative mammography in a svmptomatic population. Clin Radiol 1991:44:13-5.

11 Mann BD, Giuliano AE, Bassett LW, Barber MS, Hallauer W, Morton DL. Delayed diagnosis of breast cancer as a result of normal mammograms. Arch Surg 1983;118:23-4.

12 Banerjee AK, Walters TK, Burke M. Open access mammography. Lancet 1988;ii:336.

13 Hansell DM, Cooke JC, Patsons CA. The accuracy of mammography alone and in combination with clinical examination in the detection of breast cancer. Clin Radiol 1988:39:150-3.

14 Dixon JM, Anderson TJ, Lamb J, Nixon SJ, Forrest APM. Fine needle aspiration cytology, in relationships to clinical examination and mammography in the diagnosis of a solid breast mass. Br f Surg 1984;71:593-6.

5 Smallwood J, Herbert A, Guyer P, Taylor I. Accuracy of aspiration cytology in the diagnosis of breast disease. Br f Surg 1985;72:841-3.

16 Ashley S, Royle GT, Corder A, Herbert A, Guyer PB, Rubin CM, et al. Clinical, radiological and cytological diagnosis of breast cancer in young women. Br $\mathcal{F}$ Surg 1989; 76:835-7.

17 Yelland A, Graham MD, Trott PA, Ford HT, Coombes RC, Gazet J-C, et al. Diagnosing breast carcinoma in young women. BMF 1991;302:618-20.

18 Dixon JM, Lamb J, Anderson TJ. Fine needle aspiration of the breast: importance of the operator. Lancet 1983;ii:564.

(Accepted 25 November 1991 )

\section{Ventricular fibrillation}

- Defibrillate at $200 \mathrm{~J}$. Check pulse; 15 chest compressions while recharging; see monitor

- Defibrillate at $200 \mathrm{~J}$. Check pulse; 15 chest compressions while charging to $360 \mathrm{~J}$; see monitor

- Defibrillate at $360 \mathrm{~J}$. Check pulse; see monitor

- Intubate the trachea

- Give adrenaline $1 \mathrm{mg}$ intravenously ${ }^{\star}$

- Defibrillate at $360 \mathrm{~J}$

- Give lignocaine $100 \mathrm{mg}$ intravenously

- Defibrillate at $360 \mathrm{~J}$

- Consider (a) changing defibrillator and giving $360 \mathrm{~J}$, (b) changing paddles to anteroposterior and giving $360 \mathrm{~J}$, and $(c)$ giving other drugs (bretylium, procainamide, and bicarbonatef) and then defibrillating at $360 \mathrm{~J}$.

\section{Asystole}

- Check leads

- Check gain

- If ventricular fibrillation cannot be excluded defibrillate as for ventricular fibrillation: $200 \mathrm{~J}, 200 \mathrm{~J}, 360 \mathrm{~J}$. Then give drugs as in the case when ventricular fibrillation can be excluded

- If ventricular fibrillation can be excluded give adrenaline $1 \mathrm{mg}$ intravenously, ${ }^{\star}$ then atropine $2 \mathrm{mg}$ intravenously, and then consider pacing. $\ddagger$

\section{Electromechanical dissociation}

- Exclude tamponade, tension pneumothorax, hypovolaemia, and massive pulmonary embolism

- Give adrenaline $1 \mathrm{mg}$ intravenously ${ }^{\star}$

- Consider calcium chloride $10 \mathrm{ml} \mathrm{10 \%} \mathrm{if} \mathrm{hyperkalaemia,}$ hypocalcaemia, or overdose of calcium antagonists is present.

\section{Note}

- If intravenous access fails give adrenaline, atropine, or lignocaine in double the dose down the endotracheal tube

- Continue cardiopulmonary resuscitation for up to 2 minutes after each drug. Do not interrupt resuscitation for more than $10 \mathrm{~s}$ except to defibrillate.

\section{Drug doses}

- Adrenaline $1 \mathrm{mg}$ (10 ml 1:10000)

- Bicarbonate $1 \mathrm{mmol} / \mathrm{kg}$ ( $1 \mathrm{ml} 8 \cdot 4 \%$ solution is $1 \mathrm{mmol}$; $50 \mathrm{ml}$ is standard dose)

- Bretylium tosylate $5 \mathrm{mg} / \mathrm{kg}$ (if repeat use $10 \mathrm{mg} / \mathrm{kg}$ )

- Procainamide $100 \mathrm{mg}$ intravenously.

*Adrenaline is the drug of first choice: it increases myocardial and cerebral blood flow during cardiac compressions so give it every 5 minutes during prolonged resuscitation.

tAdequate ventilation is more appropriate than bicarbonate in relieving the acidosis: without ventilation bicarbonate may paradoxically worsen the intracellular acidosis (extracellular carbon dioxide rapidly moves back into the cell in response to the high extracellular bicarbonate) and in excess can itsel produce intractable arrhythmias. Use only in prolonged resuscitation.

Intracardiac injections are not recommended. They rarely reach the intended ventricle and may produce prolonged interruption of chest compressions (as well as having numerous complications-pneumothorax; myocardial and coronary artery laceration; arrhythmias with intramyocardial adrenaline).

$\ddagger$ Pacing is appropriate only when there is some evidence of electrical activity - for example, $P$ waves. Use transvenous ventricular pacing wire (transthoracic pacing is less effective) While preparing to pace in complete heart block use fist pacing or atropine $(0.6 \mathrm{mg}$ every 5 minutes to keep pulse above 60 beats $/ \mathrm{min}$, maximum $2 \mathrm{mg}$ ) or isoprenaline infusion (start at $2 \mu \mathrm{g} / \mathrm{min}$ )

Postresuscitation care: Involve a senior doctor in the decisions. Transfer to intensive care for monitoring (check 12 lead electrocardiogram; arterial blood gases; urea and electrolytes; chest radiogram; urine output) and treatment (give $100 \%$ oxygen and consider elective ventilation; lignocaine infusion (p 292) after ventricular fibrillation or tachycardia). - T J HODGETTS

\section{Principal source}

Fvans TR ed $A B C$ of resuscitation 2nd ed London: British Medical Journal, 1990. (Incorporating 1989 guidelines of the United Kingdom Resuscitation Council.

Anyone may submit an update box; all boxes are peer reviewed. 